\title{
(2) OPEN ACCESS \\ Patient values and preferences on valve replacement for aortic stenosis: a systematic review
}

\author{
Anja Fog Heen (ㄷ, ${ }^{1}$ Lyubov Lytvyn, ${ }^{2}$ Michael Shapiro, ${ }^{3}$ Gordon Henry Guyatt, ${ }^{2}$ \\ Reed Alexander Cunningham Siemieniuk, ${ }_{1}^{2}$ Yuan Zhang, ${ }^{2}$ Veena Manja, ${ }^{4,5}$ \\ Per Olav Vandvik, ${ }^{6}$ Thomas Agoritsas ${ }^{2,7}$
}

- Additional material is published online only. To view please visit the journal online (http://dx.doi.org/10.1136/ heartjnl-2020-318334).

Department of Medicine, Innlandet Hospital Trust Gjøvik Hospital, Brumunddal, Norway ${ }^{2}$ Department of Health Research Methods, Evidence, and Impact, McMaster University Faculty of Health Sciences, Hamilton, Ontario, Canada

${ }^{3}$ Chicago, Illinois, USA

${ }^{4}$ Department of Surgery, University of California Davis, Sacramento, California, USA ${ }^{5}$ Department of Medicine, Veterans Affairs Northern California Health Care System, Mather, California, USA

${ }^{6}$ Institute of Health and Society, University of Oslo, Oslo, Norway ${ }^{7}$ Division of General Internal Medicine, Department of Medicine, University Hospitals of Geneva, Geneva, Switzerland

\section{Correspondence to}

Dr Anja Fog Heen, Dept. of Medicine, Innlandet Hospital

Trust Gjøvik Hospital, 2819

Gjøvik, Norway;

anjaheen@gmail.com

AFH and $\mathrm{LL}$ contributed equally.

Received 24 September 2020 Revised 15 January 2021 Accepted 18 January 2021

Published Online First 9 February 2021

Check for updates

(C) Author(s) (or their employer(s)) 2021. Re-use permitted under CC BY-NC. No commercial re-use. See rights and permissions. Published by BMJ.

To cite: Heen AF, Lytvyn L, Shapiro M, et al. Heart 2021;107:1289-1295.

\section{ABSTRACT}

The review aims to summarise evidence addressing patients' values, preferences and practical issues on deciding between transcatheter aortic valve insertion (TAVI) and surgical aortic valve replacement (SAVR) for aortic stenosis. We searched databases and grey literature until June 2020. We included studies of adults with aortic stenosis eliciting values and preferences about treatment, excluding medical management or palliative care. Qualitative findings were synthesised using thematic analysis, and quantitative findings were narratively described. Evidence certainty was assessed using CERQual (Confidence in the Evidence from Reviews of Qualitative Research) and GRADE (Grading of Recommendations Assessment, Development and Evaluation). We included eight studies. Findings ranged from low to very low certainty. Most studies only addressed TAVI. Studies addressing both TAVI and SAVR reported on factors affecting patients' decisionmaking along with treatment effectiveness, instead of trade-offs between procedures. Willingness to accept risk varied considerably. To improve their health status, participants were willing to accept higher mortality risk than current evidence suggests for either procedure. No study explicitly addressed valve reintervention, and one study reported variability in willingness to accept shorter duration of known effectiveness of TAVI compared with SAVR. The most common themes were desire for symptom relief and improved function. Participants preferred minimally invasive procedures with shorter hospital stay and recovery. The current body of evidence on patients' values, preferences and practical issues related to aortic stenosis management is of suboptimal rigour and reports widely disparate results regarding patients' perceptions. These findings emphasise the need for higher quality studies to inform clinical practice guidelines and the central importance of shared decisionmaking to individualise care fitted to each patient.

\section{INTRODUCTION}

Severe aortic stenosis is a common valvular disease occurring among approximately $3 \%$ of people over 75 years old that results in significant morbidity and mortality. ${ }^{1}$ With increasing severity of stenosis, patients often experience chest pain, syncope and heart failure. ${ }^{2}$ Treatment options include surgical aortic valve replacement (SAVR) or a minimally invasive approach, transcatheter aortic valve insertion (TAVI). Benefits of TAVI include shorter hospital stay and quicker recovery; however, longterm outcome data are scarce but emerging. ${ }^{3}$
In 2016 a BMJ Rapid Recommendations guideline (BMJ RapidRecs) was published regarding the choice of TAVI versus SAVR for patients with aortic stenosis at low to intermediate surgical risk. ${ }^{4}$ To inform the guideline, a systematic review addressing patient values and preferences was conducted. ${ }^{5}$ Since 2016, new trials with longer follow-up have been published, ${ }^{6} 7$ requiring updated evidence synthesis and guidance. This article is an update of the previous review of patient values and preferences about TAVI versus SAVR. ${ }^{5}$

\section{METHODS}

We followed the MOOSE (Meta-analyses Of Observational Studies in Epidemiology) checklist (online supplemental appendix 1). The protocol was registered at PROSPERO (International Prospective Register of Systematic Reviews) (CRD42016041907).

\section{Search strategy}

We searched MEDLINE, EMBASE and PsycINFO via OVID, using a combination of keywords and subject headings for 'aortic stenosis' and 'valve replacement', as well as a validated methodological search filter for values and preferences studies. ${ }^{8}$ We updated the previous search until 16 June 2020 (online supplemental appendix 2), without language or publication status restrictions. We searched for grey literature via relevant conference abstracts, theses and dissertations (using the keywords 'aortic stenosis' and 'preference' or 'experience'), and the reference lists of eligible studies.

\section{Study selection}

We included studies with participants $\geq 18$ years with aortic stenosis whose values and preferences related to the decision to undergo TAVI or SAVR were elicited. We considered values and preferences as 'the relative importance patients placed on the outcomes' for treatment decisions. ${ }^{9}$ We excluded studies not reporting original data, case reports, studies reporting health-related quality of life before and after treatment, and studies that transformed quality of life measures into utility values, because quality of life was assessed in the associated systematic review of treatment effectiveness informing the BMJ RapidRecs. ${ }^{3}$ Our initial review ${ }^{5}$ did not include studies reporting values and preferences focused solely on medical management or 
palliative care of aortic stenosis. We therefore did not include them in this update and focused solely on TAVI and SAVR.

\section{Data collection and synthesis}

Two authors (AFH, LL) independently screened titles and abstracts using prespecified criteria after conducting calibration exercises. The authors reviewed full-text articles independently and in duplicate and resolved disagreements by discussion or consultation with a third reviewer (TA). We contacted the authors of two abstracts that were ultimately excluded and corresponded with two authors of included studies for further information.

Two reviewers (AFH, LL) independently abstracted participant demographics, clinical characteristics, methods and findings. We conducted thematic analysis on qualitative results, ${ }^{10}$ coding and synthesising primary quotations from study participants and author-reported summaries and themes. Across eligible studies, we also abstracted patient-important practical issues (ie, how a treatment can affect patients' daily life) related to decisions to undergo treatment and categorised findings using a developed generic framework, described elsewhere. ${ }^{11}$ The review authors resolved disagreements through discussion or by consulting a third party (TA).

\section{Quality assessment}

For studies reporting qualitative outcomes, we assessed study quality using the qualitative research checklist of the Critical Appraisal Skills Programme. ${ }^{12}$ For studies reporting quantitative outcomes, we assessed risk of bias using the instrument developed by Zhang et al, ${ }^{13}$ appraising the following domains: study population, measurement and data analysis.

\section{Certainty of evidence}

Beyond quality assessments of each study, we assessed the overall certainty of evidence using Grading of Recommendations Assessment, Development and Evaluation (GRADE) for quantitative findings ${ }^{13} 14$ and Confidence in the Evidence from Reviews of Qualitative Research (CERQual) for qualitative findings. ${ }^{15}$ We rated certainty of evidence as high, moderate, low or very low for each finding. Findings started at high certainty and rated them down if there were concerns in one or more domains. ${ }^{16}$ For CERQual, certainty could be rated down for methodological limitations, coherence, adequacy and relevance. ${ }^{15}$ For GRADE, certainty could be rated down for risk of bias, inconsistency, indirectness, imprecision and publication bias. ${ }^{13} 14$

\section{Incorporation into BMJ RapidRecs}

The BMJ RapidRecs are developed in a collaboration between the not-for-profit MAGIC Evidence Ecosystem Foundation ${ }^{17}$ and The BMJ. ${ }^{18}$ Recommendations and associated reviews are updated given potentially practice-changing new evidence, ${ }^{4}$ and this update is part of this process. Findings will be appraised by an independent guideline panel, without conflict of interests, including patient partners, front-line clinicians and methodologists working together to translate emerging research to userfriendly and trustworthy recommendations, evidence summaries and tools for shared decision-making. ${ }^{419}$

\section{RESULTS}

We identified 1230 unique titles and abstracts and reviewed 51 in full text (figure 1). Eight studies, reported in ten articles, were deemed eligible, with new six studies since the original review. ${ }^{20-25}$ Study findings are described narratively and include

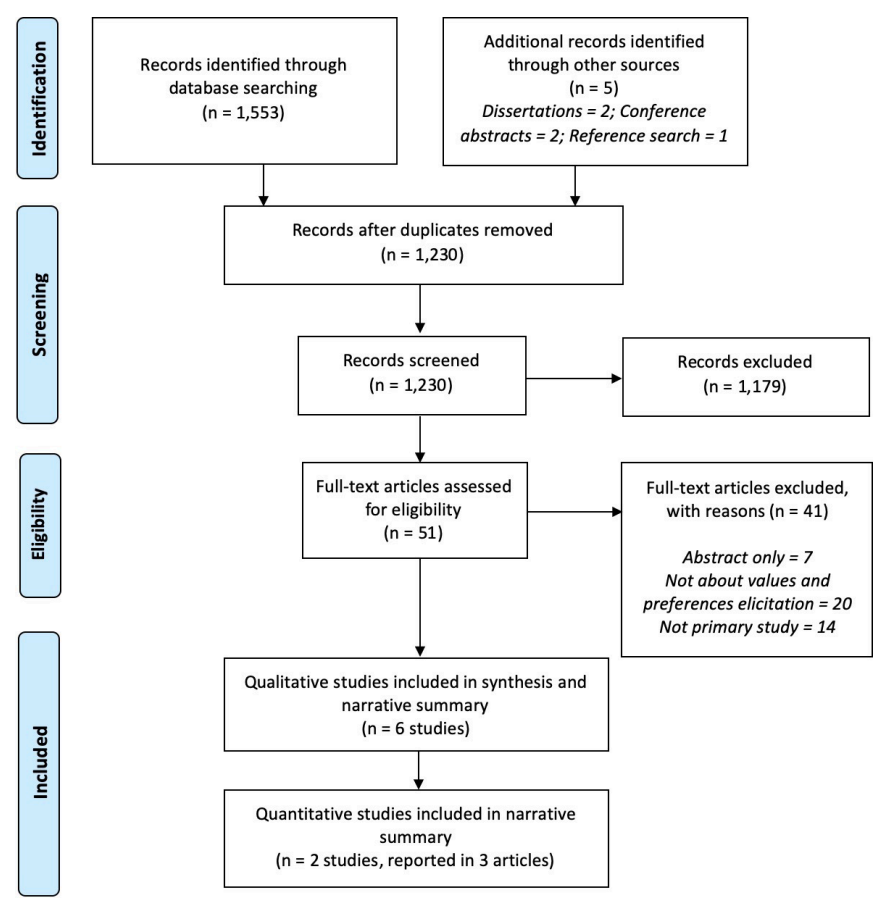

Figure 1 PRISMA study flow diagram. PRISMA, Preferred Reporting Items for Systematic Reviews and Meta-Analyses.

exemplar quotes from patients in the primary studies when available. Quantitative results are presented in table 1. Further details of the qualitative results are reported in online supplemental appendix table 5 .

\section{Study characteristics}

Studies were conducted in Canada, Norway, Sweden and USA (table 2). Of the quantitative studies, the sample sizes were $219^{25}$ and $439 .{ }^{26}$ Of the qualitative studies, one study included 333 participants, ${ }^{20}$ while the others ranged from 10 to 46 participants. ${ }^{21-24} 27$ Authors' conflicts of interest and study funding were variably reported. Two studies reported funding from a TAVI valve manufacturer (online supplemental appendix table 2). ${ }^{20} 25$ All but one study included participants with confirmed severe aortic stenosis, ${ }^{20-24} 2627$ and the remaining included participants with self-reported diagnosis without specifying severity. ${ }^{25}$ Participants were balanced in sex and were on average between 75 and 86 years old, except one study with $26 \%$ of participants aged $19-59$ years old. ${ }^{25}$ Surgical risk was variable across studies, ${ }^{21} 23242627$ unknown or unspecified. ${ }^{20225}$

\section{Study quality and certainty of evidence}

Most of the qualitative studies had methodological limitations, ${ }^{20-22} 2427$ the most common issues being inappropriate or unclear sampling and recruitment strategy, limited description of data analysis and strategies to enhance study rigour (online supplemental appendix table 3). For the quantitative studies, there were limitations in almost all domains, with the most concern being about participant selection, outcome presentation and data analysis (online supplemental appendix table 4). The certainty of findings ranged from low to very low (table 1, online supplemental appendix 1). The majority of studies assessed values and preferences on one intervention alone. 
Table 1 GRADE summary of findings

\begin{tabular}{|c|c|c|c|c|}
\hline Health state/outcome (timeframe) & $\begin{array}{l}\text { Study design } \\
\text { ( } \mathrm{n}=\text { participants) }\end{array}$ & Estimate of effect, mean (SD) unless otherwise stated & $\begin{array}{l}\text { Certainty of } \\
\text { evidence }\end{array}$ & Interpretation of finding \\
\hline Mortality (30 days) & $\begin{array}{l}\text { Adaptive swing weighting } \\
\left(109^{*}\right)\end{array}$ & $\begin{array}{l}\text { Maximum acceptable increase in risk in exchange from } \\
\text { SAVR to TAVI =3.7\% (3.0)t. }\end{array}$ & Very low§ף** & $\begin{array}{l}\text { The risk willingness of trading a reduction in mortality risk ( } 30 \text { days) } \\
\text { for a less invasive procedure was uncertain and highly variable. }\end{array}$ \\
\hline $\begin{array}{l}\text { Mortality and aortic stenosis-related } \\
\text { symptoms and concerns (lifetime) }\end{array}$ & Standard gamble (429) & $\begin{array}{l}\text { Median risk willingness=25\% (IQR 25\%-50\%). } \\
\text { No risk }(0 \%)=104(23 \%) \text {. } \\
\text { Low risk }(0 \%-8 \%)=26(6 \%) \text {. } \\
\text { High risk }(>8 \%-50 \%)=224(51 \%) \text {. } \\
\text { Prohibitive risk }(>50 \%-95 \%)=68(15 \%) \text {. } \\
95 \%-100 \%=17(4 \%)\end{array}$ & Low§ף & $\begin{array}{l}\text { The risk willingness of trading a reduction in mortality risk for full } \\
\text { health with the procedure is highly variable among participants and } \\
\text { across risk groups. }\end{array}$ \\
\hline Disabling non-fatal stroke ( 30 days) & $\begin{array}{l}\text { Adaptive swing weighting } \\
\left(110^{\star}\right)\end{array}$ & $\begin{array}{l}\text { Maximum acceptable increase in risk in exchange from } \\
\text { SAVR to TAVI=6.7\% (5.7)t. }\end{array}$ & Very low§ף** & $\begin{array}{l}\text { The risk willingness of trading a reduction in risk of disabling stroke } \\
\text { for a less invasive procedure was uncertain and highly variable. }\end{array}$ \\
\hline Independence (30 days) & $\begin{array}{l}\text { Adaptive swing weighting } \\
\left(131^{*}\right)\end{array}$ & $\begin{array}{l}\text { Maximum acceptable reduction in benefit in exchange } \\
\text { from SAVR to TAVI=13.9\% (11.8)t. }\end{array}$ & Very low§ף** & $\begin{array}{l}\text { The risk willingness of trading an increase of independence for a less } \\
\text { invasive procedure was uncertain and highly variable. }\end{array}$ \\
\hline Requirement for dialysis (1 year) & $\begin{array}{l}\text { Adaptive swing weighting } \\
\left(132^{*}\right)\end{array}$ & $\begin{array}{l}\text { Maximum acceptable increase in risk in exchange from } \\
\text { SAVR to TAVI=6.2\% (5.6)t. }\end{array}$ & Very low§ף** & $\begin{array}{l}\text { The risk willingness of trading a reduction in the requirement for } \\
\text { dialysis at } 1 \text { year for a less invasive procedure was uncertain and } \\
\text { highly variable. }\end{array}$ \\
\hline New permanent pacemaker ( 1 year) & $\begin{array}{l}\text { Adaptive swing weighting } \\
\left(131^{\star}\right)\end{array}$ & $\begin{array}{l}\text { Maximum acceptable increase in risk in exchange from } \\
\text { SAVR to TAVI=7.0\% (5.7)‡. }\end{array}$ & Very low§ף** & $\begin{array}{l}\text { The risk willingness of trading a reduction in permanent pacemaker } \\
\text { insertion for a less invasive procedure was uncertain and highly } \\
\text { variable. }\end{array}$ \\
\hline $\begin{array}{l}\text { Time over which the procedure has been } \\
\text { proven to work }\end{array}$ & $\begin{array}{l}\text { Adaptive swing weighting } \\
\left(131^{\star}\right)\end{array}$ & $\begin{array}{l}\text { Maximum acceptable decrease in duration that the } \\
\text { procedure is known to work in exchange from SAVR to } \\
\text { TAVI=17.4 years (16.9)‡. }\end{array}$ & Very low§ $\rrbracket^{* *}$ & $\begin{array}{l}\text { The risk willingness of trading the expected duration or a new valve } \\
\text { for a less invasive procedure was uncertain and highly variable. }\end{array}$ \\
\hline
\end{tabular}

\section{Values and preferences regarding outcomes of treatment}

None of the studies presented participants' values and preferences based on a comprehensive assessment of the beneficial and adverse outcomes related to SAVR versus TAVI, nor did any studies report patient preferences about choosing between TAVI versus SAVR. Instead, studies focused on preferences about a selection of attributes in isolation. None of the studies addressed the lifelong management of treatment of valve failure.

\section{Durability and valve reintervention}

No study directly addressed how participants valued valve failure nor the risk and timing of reintervention. One study provided very low certainty of evidence regarding preferences about durability, illustrating considerable variability in patients' willingness to accept a shorter duration of the effectiveness of TAVI compared with SAVR..$^{25}$ A subgroup analysis suggested this variability may be partly explained by the fact that participants under 60 years old were more concerned with valve duration than those over $60 .^{25}$

\section{Mortality and risk willingness related to the decision to undergo treatment}

All studies addressed mortality. ${ }^{20-23} 2627$ Studies did not explicitly distinguish between perioperative mortality, mortality from natural progression of disease or all-cause mortality. Participants viewed declining treatment to be worse than accepting the risk related to the procedure, ${ }^{23}$ and thus were commonly willing to accept a high perioperative mortality risk. The importance of mortality can be illustrated by the following participant quote:

And if I would have turned it [TAVI assessment] down, I mean, who knows how long I would last? Not much longer, probably, you know. ${ }^{27}$

Risk willingness varied considerably. ${ }^{26}$ Overall, participants were willing to accept a higher mortality risk than current evidence suggests for TAVI, regardless of the fact that actual mortality risk is lower with TAVI than SAVR. ${ }^{6725}$
For some participants, increasing life expectancy was more commonly a preference expressed by their families than by themselves, ${ }^{23}{ }^{24}$ as exemplified by the following quote:

We did not discuss it too much the physician and I either. (...) He just asked if I wanted (the treatment) and I accepted. (...) I did it for the others' sake as well. ${ }^{23}$

\section{Quality of life as reasons to undergo treatment}

All but one study ${ }^{26}$ reported improvements in health-related quality of life domains (eg, physical function, emotional wellbeing) as reasons to undergo treatment. ${ }^{20} 2123-2527$ Common themes were desire for symptom relief and improved function. Respondents often described improved quality of life as the ability to do a specific activity, to regain or maintain independence, $^{21-24} 27$ to return to activities they had given up and to reconnect with their social network. ${ }^{27}$ A participant's perspective was:

We belong to a walking club [... ], but I've quit that in the last probably 3 or 4 months because I just couldn't keep up with them. They'd go and I said, "Well, I'll go half way" and they still got back before I did, so I said, "I guess I'll quit because it just hinders you guys." 27

The desire to achieve the best possible health was closely intertwined with participants' ability to fulfil obligations towards family and friends and day-to-day activities when deciding on treatment. ${ }^{2021232427}$ Participants expressed not wanting to be a burden to relatives. ${ }^{202327}$ A participant noted the effect of their declining health on their partner, expressing:

And this is passed on to my wife, of course. If I can't take [wife] to dance, she doesn't get to go either, you know what I mean? ${ }^{27}$

\section{Concerns of pain}

Pain was a concern with SAVR. One participant stated:

Quite a bit of pain in the chest area, having your chest cracked open. $^{22}$ 


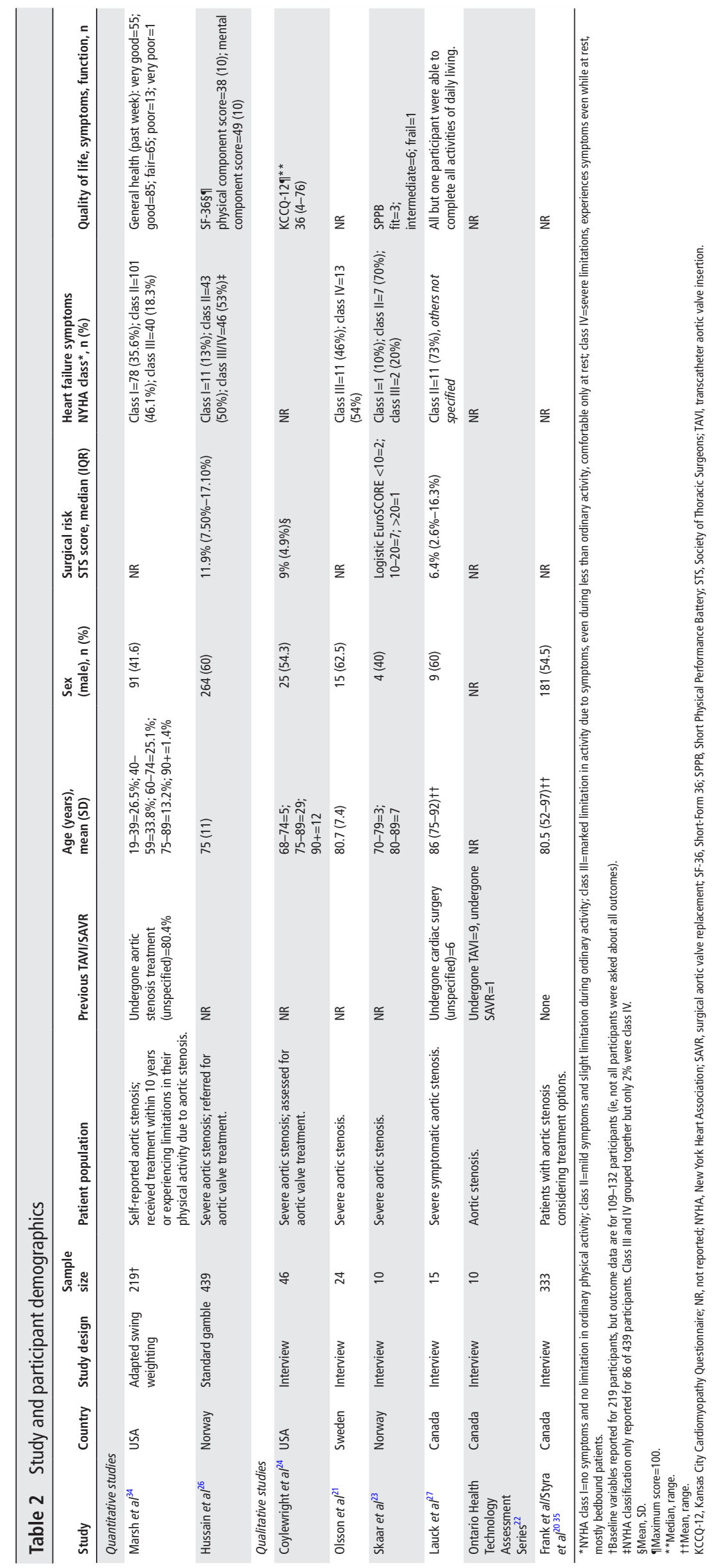

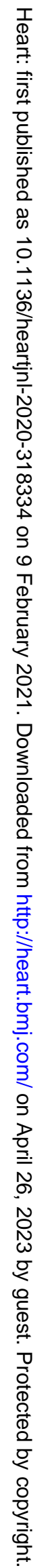


Those who had TAVI described minimal pain, with a participant saying:

And I didn't have any pain afterwards at all. I didn't even know that I'd had incisions in my groin. I just didn't know it was there. It was amazing. ${ }^{22}$

\section{Acute kidney injury and stroke}

Two studies addressed acute kidney injury. ${ }^{24} 25$ One addressed the possibility of dialysis as a patient concern related to potential TAVI complications. ${ }^{24}$ The other study provided evidence regarding patients' willingness to accept the risk of needing dialysis within 1 year after the procedure. ${ }^{25}$ Patients in one study frequently expressed that they were afraid of the possibility of a stroke. $^{21}$

\section{Practical issues related to valve replacement}

Several studies addressed participants' concerns regarding practical issues, such as invasiveness, length of hospital stay and recovery time. ${ }^{2122} 25$ Regarding TAVI, one participant stated:

It's easy by comparison to an open-heart surgery. That is just a big plus. Can you imagine having your chest cut right open and taking months to recover? ${ }^{27}$

Overall, patients reported the longer hospital stay and recovery time with SAVR, compared with TAVI, as a major concern. ${ }^{22}$ None of the studies mentioned the need for-and accessibility to-cardiac rehabilitation after SAVR or TAVI.

\section{Decision-making process and support}

Respondents perceived physicians as essential sources of information and decision-making guidance and as facilitators of referral for TAVI, and participants stressed the importance of a trusting relationship with their physician(s). ${ }^{21}{ }^{23}$ The experience of receiving rigorous advice from their physician was important in decision-making, illustrated by the following participant quote:

When I'm with my doctor, I believe he is competent enough just to see what my problem is and how it can be treated. ${ }^{27}$

A number of studies, however, reported the possibility that physicians might not act in a trustworthy way, which motivated participants to seek a second opinion. ${ }^{2123}{ }^{27}$ Overall, participants took into account a variety of medical, functional and social factors in their decision-making. ${ }^{20-24} 27$

\section{Accessibility and cost of the procedure}

Participants who lived away from hospitals that offered the procedure reported greater difficulty accessing TAVI. ${ }^{22}$ Several studies reported participants' concern about burden of personal cost due to travel, meals and accommodation, ${ }^{22} 27$ exemplified by the following participant quote:

My family wanted to be there when I had the surgery, so there was ... overnight accommodation ... and meals, and so on. And someone to help with the driving ... It was basically ... personal expenses. $^{22}$

Given the expected shorter length of hospital stay with TAVI, some patients perceived these costs to be much lower than with SAVR. ${ }^{22}$

\section{DISCUSSION}

Our search identified eight studies that examined patients' values, preferences and practical issues related to aortic stenosis treatment. ${ }^{20-25}$ They provided limited evidence regarding how participants explicitly value and balance benefits and harms associated with TAVI and SAVR. ${ }^{20-27}$ Most studies addressed only TAVI, and those that addressed both TAVI and SAVR did not specify the information they had provided to participants about the relative merits and burdens of the two procedures. Study participants were concerned about treatment complications, and willingness to accept procedural risk varied considerably. Participants of the qualitative studies rarely reported perspectives regarding specific outcomes (eg, stroke), but rather highlighted and valued fast return to function, independence, and social and daily activities. In terms of decision-making in general, trust in physicians and medical teams was very important in the decision. For practical issues, accessibility of the procedure and associated costs (eg, travel for themselves and their caregivers) were commonly reported.

Recent randomised trials, ${ }^{28}{ }^{29}$ as well as previously published trials with longer follow-up, ${ }^{67}$ have added up to the current body of evidence comparing TAVI and SAVR. ${ }^{3}$ Taken together, this evidence tends to show substantial short-term benefits of TAVI on outcomes important to patients with severe aortic stenosis at low and intermediate preoperative surgical risk, along with a substantially reduced burden of treatment.

However, valve durability with TAVI remains uncertain over the longer term due to limited follow-up compared with SAVR. An important concern is that TAVI might require valve reintervention much earlier than SAVR. This issue is particularly crucial for younger populations, as their life expectancy puts them at higher risk of needing one-or more-reinterventions. Unfortunately, our systematic review provides limited evidence on how patients may value differing valve durability and the risk of reinterventions. Indeed, only one study reported on patients' perceptions about willingness to accept a shorter duration of effectiveness of TAVI compared with SAVR, showing important variability. This study had methodological limitations and was funded by a valve device company. ${ }^{25}$

Another issue that varies with age is how the relative effects of TAVI translate in terms of absolute differences: because patients present a higher baseline mortality, TAVI is likely going to result in larger absolute reductions in deaths among older rather than younger patients. The balance of benefits and harms of TAVI versus SAVR will thus highly depend on age-as a proxy of life expectancy-as well as comorbidities. ${ }^{4}$ The age or baseline risk threshold at which patients would consider the balance between benefits, harms and burden (including the risk of reintervention) in favour of either TAVI or SAVR remains thus far insufficiently explored. Current inference on these issues is further limited by the fact that several studies asked patients to trade off outcomes without basing the options on current best evidence. For example, they present unrealistic outcome risk options that were beyond the range of actual risks reported in trials. ${ }^{467}$ The trade-off of outcomes may thus be misinformed or even misguided in such studies. Even less explored are patients' values and preference regarding the possible sequence of valve interventions.

\section{Strengths and limitations}

Our review has several strengths. First, we prospectively registered the protocol and followed study reporting criteria. Second, we conducted a comprehensive search, including grey literature, up to June 2020 . Third, we assessed study quality using recommended instruments, ${ }^{912} 15$ as well as using standardised methods to address the overall certainty of evidence for both quantitative and qualitative findings. ${ }^{13} 1430$ Fourth, the inclusion of a 
patient partner as a coauthor enriched the framework used for thematic analysis. Finally, we abstracted data regarding patientimportant practical issues, which shed light on areas important for decision-making that are rarely included when developing guidelines.

Our review has also limitations. First, we excluded studies looking at health-related quality of life for patients with aortic stenosis before and after therapy because these studies do not directly report on patient preferences. Second, due to the considerable heterogeneity of the types of studies included, we were not able to explore potential differences in values and preferences for subgroups of participants. Finally, our review highlights limitations of current evidence in the field, and particularly the lack of data on key outcomes and practical issues which guideline panels and patients need to inform decision-making.

\section{CONCLUSION AND AVENUES FOR FUTURE RESEARCH}

In parallel to new evidence on the effectiveness and durability of interventions, we need higher quality evidence on patients' values and preferences on all key outcomes, as well as better

Key messages

What is already known on this subject?

- Transcatheter aortic valve insertion (TAVI) is increasingly offered as an alternative treatment option to surgical aortic valve replacement (SAVR) for severe, symptomatic aortic stenosis, but its long-term durability remains uncertain.

- There is limited evidence on values, preferences and practical issues that are important to patients with aortic stenosis regarding the trade-offs of benefits and harms of TAVI compared with SAVR.

\section{What might this study add?}

- We provide a critical appraisal of empirical evidence on values and preferences related to aortic stenosis treatment.

- Current evidence suggests there is considerable variability among patients' values and preferences regarding the outcomes associated with TAVI or SAVR, as well as regarding the duration that the procedure has been proven to be effective.

- To improve their health status, participants were willing to accept higher mortality risk than current evidence suggests for either procedure, although this evidence was of low to very low certainty.

- Overall, participants preferred minimally invasive procedures with a shorter hospital stay and recovery time and also reported concerns regarding postsurgical pain and costs.

- An important limitation of this evidence is that no study presented participants current best evidence on all benefits and risks for both procedures, including valve durability, when enquiring for their preferred option.

\section{How might this impact on clinical practice?}

- Discussions regarding individual patients' values and preferences, focusing on the key outcomes and practical issues identified in this paper, can support shared decisionmaking about the best aortic stenosis treatment option for patients.

- This evidence can also inform the updates of health technology assessment and clinical practice guidelines on TAVI and SAVR. insight on what practical issues matter most to them. Future studies should be conducted in a broad and representative array of patients with severe, symptomatic aortic stenosis with variable risk profiles and comorbidities. They should also be informed by current best evidence on benefits and harms, rather than hypothetical (or even implausible) effects. Evidence from real-life decision-making, for example by using encounter decision aids, may better capture actual values and preferences to inform stakeholders such as guideline developers. ${ }^{1931}$

Another priority should be to identify key practical issues for decision-making. New frameworks have been proposed to better structure searching, evidence synthesis and inclusion in the guideline-making process of patient-important practical issues. ${ }^{19} 3233$ Indeed, in highly preference-sensitive decisions such as whether to undergo TAVI or SAVR, practical issues related to each intervention and how they may affect patients' daily life may dominate shared decision-making conversations. $^{9}$

Acknowledgements We thank the members of the BMJ Rapid Recommendations panel for critical feedback on outcomes and selection that informed this systematic review.

Contributors AFH led and coordinated the project. TA and POV provided supervision. AFH, LL and TA screened the studies for eligibility. AFH and LL extracted the data, assessed study risk of bias and synthesised the data. AFH, LL and TA assessed the quality of the body of evidence. All study authors were involved in the interpretation and discussion of the results. AFH and LL drafted the manuscript, and all authors critically revised the manuscript. All authors approved the final version of the article. AFH is the guarantor.

Funding The authors have not declared a specific grant for this research from any funding agency in the public, commercial or not-for-profit sectors.

Competing interests $A F H, L L, G G, R A C S, T A, P O V$ and $Y Z$ are members of the GRADE working group. YZ designed the risk of bias tool and the GRADE evaluation for values and preferences studies. There are no other relationships or activities that could appear to have influenced the submitted work.

Patient and public involvement statement Outcomes of interest included for this review were established by a multidisciplinary guideline panel that included three patient partners. One patient partner (MMS) from the guideline panel was included as a coauthor of this study. MMS was involved in the interpretation of study results and provided feedback on the manuscript.

Patient consent for publication Not required.

Provenance and peer review Not commissioned; externally peer reviewed. Supplemental material This content has been supplied by the author(s). It has not been vetted by BMJ Publishing Group Limited (BMJ) and may not have been peer-reviewed. Any opinions or recommendations discussed are solely those of the author(s) and are not endorsed by BMJ. BMJ disclaims all liability and responsibility arising from any reliance placed on the content. Where the content includes any translated material, BMJ does not warrant the accuracy and reliability of the translations (including but not limited to local regulations, clinical guidelines, terminology, drug names and drug dosages), and is not responsible for any error and/or omissions arising from translation and adaptation or otherwise.

Open access This is an open access article distributed in accordance with the Creative Commons Attribution Non Commercial (CC BY-NC 4.0) license, which permits others to distribute, remix, adapt, build upon this work non-commercially, and license their derivative works on different terms, provided the original work is properly cited, appropriate credit is given, any changes made indicated, and the use is non-commercial. See: http://creativecommons.org/licenses/by-nc/4.0/.

ORCID iD

Anja Fog Heen http://orcid.org/0000-0002-8873-7028

\section{REFERENCES}

1 Osnabrugge RLJ, Mylotte D, Head SJ, et al. Aortic stenosis in the elderly: disease prevalence and number of candidates for transcatheter aortic valve replacement: a meta-analysis and modeling study. J Am Coll Cardiol 2013;62:1002-12.

2 Fau TJ, Fau HO, Fau SF, et al. Spontaneous course of aortic valve disease. (0195-668X (print)). 
3 Siemieniuk RA, Agoritsas T, Manja V, et al. Transcatheter versus surgical aortic valve replacement in patients with severe aortic stenosis at low and intermediate risk: systematic review and meta-analysis. BMJ 2016;354:15130.

4 Vandvik PO, Otto CM, Siemieniuk RA, et al. Transcatheter or surgical aortic valve replacement for patients with severe, symptomatic, aortic stenosis at low to intermediate surgical risk: a clinical practice guideline. BMJ 2016:i5085.

5 Lytvyn L, Guyatt GH, Manja V, et al. Patient values and preferences on transcatheter or surgical aortic valve replacement therapy for aortic stenosis: a systematic review. BMJ Open 2016;6:e014327.

6 Gleason TG, Reardon MJ, Popma JJ, et al. 5-year outcomes of self-expanding transcatheter versus surgical aortic valve replacement in high-risk patients. J Am Coll Cardiol 2018;72:2687-96.

7 Søndergaard L, Ihlemann N, Capodanno D, et al. Durability of Transcatheter and Surgical Bioprosthetic Aortic Valves in Patients at Lower Surgical Risk. J Am Coll Cardiol 2019;73:546-53.

8 Selva A, Solà I, Zhang Y, et al. Development and use of a content search strategy for retrieving studies on patients' views and preferences. Health Qual Life Outcomes 2017; 15:126

9 Zhang Y, Coello PA, Brożek J, et al. Using patient values and preferences to inform the importance of health outcomes in practice guideline development following the GRADE approach. Health Qual Life Outcomes 2017;15:52.

10 Thomas J, Harden A. Methods for the thematic synthesis of qualitative research in systematic reviews. BMC Med Res Methodol 2008;8:45.

11 Heen AF, Vandvik PO, Brandt L, et al. A framework for practical issues was developed to inform shared decision-making tools and clinical guidelines. J Clin Epidemiol 2021;129:104-13.

12 Critical. APS. CASP qualitative checklist. Available: https://casp-uk.net/casp-toolschecklists/2019 [Accessed 1 Oct 2019].

13 Zhang Y, Alonso-Coello P, Guyatt GH, et al. GRADE guidelines: 19. assessing the certainty of evidence in the importance of outcomes or values and preferences-Risk of bias and indirectness. J Clin Epidemiol 2019;111:94-104.

14 Zhang Y, Coello PA, Guyatt GH, et al. GRADE guidelines: 20. assessing the certainty of evidence in the importance of outcomes or values and preferences-inconsistency, imprecision, and other domains. J Clin Epidemiol 2019;111:83-93.

15 Lewin S, Bohren M, Rashidian A, et al. Applying GRADE-CERQual to qualitative evidence synthesis findings-paper 2: how to make an overall CERQual assessment of confidence and create a summary of qualitative findings table. Implement $\mathrm{Sci}$ 2018;13:10

16 Colvin CJ, Garside R, Wainwright M, et al. Applying GRADE-CERQual to qualitative evidence synthesis findings-paper 4: how to assess coherence. Implement Sci 2018;13:13

17 MAGIC, 2018. Available: http://magicproject.org/

18 Siemieniuk RA, Agoritsas T, Macdonald H, et al. Introduction to BMJ Rapid Recommendations. BMJ 2016;354:15191.
19 Agoritsas T, Heen AF, Brandt L, et al. Decision AIDS that really promote shared decision making: the PACE quickens. BMJ 2015;350:g7624.

20 Frank D, Kennon S, Bonaros N, et al. Trial protocol for the validation of the 'Toronto Aortic Stenosis Quality of Life (TASQ) Questionnaire' in patients undergoing surgical aortic valve replacement (SAVR) or transfemoral (TF) transcatheter aortic valve implantation (TAVI): the TASQ registry. Open Heart 2019;6:e001008.

21 Olsson K, Näslund U, Nilsson J, et al. Experiences of and coping with severe aortic stenosis among patients waiting for transcatheter aortic valve implantation. $J$ Cardiovasc Nurs 2016;31:255-61.

22 Ontario Health Technology Assessment Series. Transcatheter aortic valve implantation in patients with severe, symptomatic aortic valve stenosis at intermediate surgical risk. health quality Ontario, 2018. Available: https://www.hqontario.ca/evidenceto-improve-care/health-technology-assessment/reviews-and-recommendations/ transcatheter-aortic-valve-implantation-in-patients-with-severe-symptomatic-aorticvalve-stenosis-at-intermediate-surgical-risk

23 Skaar E, Ranhoff AH, Nordrehaug JE, et al. Conditions for autonomous choice: a qualitative study of older adults' experience of decision-making in TAVR. J Geriatr Cardiol 2017;14:42-8.

24 Coylewright M, Palmer R, O'Neill ES, et al. Patient-defined goals for the treatment of severe aortic stenosis: a qualitative analysis. Health Expect 2016;19:1036-43.

25 Marsh K, Hawken N, Brookes E, et al. Patient-Centered benefit-risk analysis of transcatheter aortic valve replacement. F1000Res 2019;8:394.

26 Hussain Al, Garratt AM, Brunborg C, et al. Eliciting patient risk willingness in clinical consultations as a means of improving decision-making of aortic valve replacement. J Am Heart Assoc 2016;5:e002828.

27 Lauck SB, Baumbusch J, Achtem L, et al. Factors influencing the decision of older adults to be assessed for transcatheter aortic valve implantation: an exploratory study. Eur J Cardiovasc Nurs 2016;15:486-94.

28 Mack MJ, Leon MB, Thourani VH, et al. Transcatheter aortic-valve replacement with a balloon-expandable valve in low-risk patients. N Engl J Med 2019;380:1695-705.

29 Popma JJ, Deeb GM, Yakubov SJ, et al. Transcatheter aortic-valve replacement with a self-expanding valve in low-risk patients. N Engl J Med 2019;380:1706-15.

30 Lewin S, Booth A, Glenton C, et al. Applying GRADE-CERQual to qualitative evidence synthesis findings: introduction to the series. Implement Sci 2018;13:2.

31 van Beek-Peeters JJAM, van Noort EHM, Faes MC, et al. Shared decision making in older patients with symptomatic severe aortic stenosis: a systematic review. Heart 2020;106:647-55.

32 Heen AF, Vandvik PO, Agoritsas T, et al. Including practical issues and patient perspectives in rapid recommendations. BMJ 2018:363:k4871.

33 Heen AF, Vandvik PO, Brandt L, et al. A framework for practical issues was developed to inform shared decision-making tools and clinical guidelines. J Clin Epidemiol 2021:129:104-13.

34 Marsh K, Hawken N, Brookes E. Patient-centered benefit-risk analysis of transcatheter aortic valve replacement [version 4; peer review: 2 approved]. F1000Res 2020;8:394.

35 Styra R, Dimas M, Svitak K, et al. Toronto aortic stenosis quality of life questionnaire (TASQ): validation in TAVI patients. BMC Cardiovasc Disord 2020;20:209. 